\title{
A Conversation with Ian Hickson
}

\author{
INTERVIEWER: Beth MOOREFIELD \\ Senior Editor, Nature Structural and Molecular Biology
}

Ian Hickson is a Professor in the Department of Cellular and Molecular Medicine and the Director of the Center for Chromosome Stability at the University of Copenhagen.

Beth Moorefield: Your group works on a mammalian translocase called PICH [Plk1-interacting checkpoint helicase], which is required to separate sister chromatids at mitotic anaphase, and the physical and functional properties of PICH that makes it uniquely suited to this purpose. I thought we could talk about what DNA structures PICH targets.

Dr. Hickson: PICH recognizes an unusual structure in mitosis called the "ultrafine anaphase bridge." When the separating sister masses of DNA come apart, they sometimes leave behind a thread of DNA that has no histones on it. It also doesn't stain with DNA dyes. The only way you can see it is by the proteins that are bound to the structure. That's why they're called "ultrafine bridges," because you can't see them without staining for the proteins. The first protein that was identified that recognizes these structures is PICH. It, to some extent, defines the structure.

Beth Moorefield: But it's not the only protein that localizes to it.

Dr. Hickson: No, it isn't. There're a lot of proteins, mainly DNA repair proteins. The main complex that binds is called the "Bloom syndrome complex," named after proteins defective in a cancer predisposition disorder called Bloom syndrome. That's the BLM protein. It has two partner proteins. One is a topoisomerase, called Topo III, and the other is a protein called RIF1 [Replication Timing Regulatory Factor 1]. They bind to these ultrafine bridges. However, the binding of BLM and Topo III and RIF1 to these bridges is entirely dependent upon PICH. PICH controls the recruitment of all the other factors to the bridge DNA.

Beth Moorefield: So, it's not actually actively disentangling the DNA?

Dr. Hickson: We don't think so. We think the topoisomerase III is actually the key enzyme for disentangling the DNA. Topoisomerases are enzymes that can unknot and disentangle catenated or entangled DNA.

Beth Moorefield: What are the physical properties of the DNA that PICH recognizes?
Dr. Hickson: We can only speculate about that. We think the DNA is conventional double-stranded DNA but at its center is entangled or catenated DNA, such that the DNA cannot come apart, and what you have to do is you have to disentangle that to allow the DNA masses to come apart. We don't think it recognizes the entanglement. It decorates the bridge all the way along its length. The question is, how could it possibly do that? How does it know where to be on the bridge?

We think there's a reason for that. We collaborate with a group in the Netherlands headed by Gijs Wuite and Erwin Peterman. They use a technique called "optical tweezers," which is a method by which you can manipulate DNA molecules using laser light in a flow cell and you can apply force to the DNA. They showed that if you stretch DNA the PICH binds to it much more efficiently than if you don't stretch the DNA. In mitosis, the DNA masses are being pulled apart and the bridge is in between. We believe the bridge is under tension; the bridge is being stretched. PICH actually recognizes the physical stretching of the DNA. We see it as a form of tension sensor. That's a little exaggerated, but that's how we see it.

The PICH has the fundamental ability to find a piece of stretched DNA in mitosis, and only in mitosis. It's an enzyme that's actually in the cytoplasm in interphase, so it only gets access to the DNA when the nuclear envelope breaks down in mitosis. It's a purely mitotic factor that's sitting outside the nucleus waiting to rush in onto the DNA.

Beth Moorefield: So, by actually using these stretched molecules, you can mimic the cellular system?

Dr. Hickson: We're doing that now. We replace the sister masses of DNA with polystyrene beads, and then we stretch a piece of DNA in between them.

Beth Moorefield: Once PICH is actually bound to the DNA, what is it actually doing to it?

Dr. Hickson: It's a DNA translocase, which means that it runs along the DNA duplex without separating the two strands. It's not a DNA helicase, which separates the two strands. It runs along the DNA, which can change the

(C) 2017 Hickson. This article is distributed under the terms of the Creative Commons Attribution-NonCommercial License, which permits reuse and redistribution, except for commercial purposes, provided that the original author and source are credited. 
structure of the DNA. We think that its main job is to recruit all the other factors, including the Bloom's complex, that then do the real business. Without protein-protein interactions, they don't get recruited.

We've reproduced that using the optical tweezer setup, where we've asked how does the Bloom protein recognize the DNA, and how do Topo III and RIF1 recognize the DNA. The thing is, they sit on a piece of DNA that they cannot recognize themselves. If you give them doublestranded DNA in vitro, they cannot bind to that. PICH binds to double-stranded DNA; but they bind to singlestranded DNA. If you coat the DNA with PICH, they now bind to the PICH-coated DNA. PICH allows the complex to bind to a piece of DNA it would never bind to normally. We don't think it manipulates the DNA structure, because if you make a catalytically dead PICH, it still recruits the factors to these bridges. It's the physical presence of PICH that then attracts all the other proteins onto there, and then they find the abnormality, the entanglement, and they disentangle it. That's our working model.

Beth Moorefield: So, it's not actually activating those factors, but rather it's working as an adapter to recruit them to the sites where they're necessary?

Dr. Hickson: We think so, although it is an enzyme, so it must be doing something to the DNA. We haven't actually worked out what that something is. It is possible, and we do have some evidence for it, that it changes DNA supercoiling. It has the ability to alter DNA supercoiling in combination with the topoisomerase. It's fairly preliminary at this stage, but we think it might be manipulating the DNA structure through tracking along the helix and imposing supercoiling on the DNA. We don't understand why that would help the situation, but a speculation would be that if the DNA is supercoiled instead of being relaxed, it actually drives decatenation more efficiently. That's been shown for other topoisomerases.

Beth Moorefield: Can you demonstrate this by using decatenation assays?

Dr. Hickson: We are doing that currently.

Beth Moorefield: Can these individual factors form complexes off the DNA?

Dr. Hickson: Yes, they can. We demonstrated that they form protein interactions. PICH bind directly to both BLM and to topoisomerase III, and it does so through conserved domains. We're fairly confident it has the ability to recognize the two proteins in solution, but they never see each other outside of mitosis because PICH is in cytoplasm and the others are in the nucleus.

Beth Moorefield: Are there specific sites of recruitment for PICH on the ultrafine bridges? Do you know how it's spreading to cover the whole bridge?

Dr. Hickson: It seems as if it gets recruited almost instantaneously to the entire length of the bridge. As soon as the bridge forms you can see PICH along the length, and however long the bridge gets, it just coats the entire thing.
We are trying to test that in vitro with these optical tweezers, but it doesn't seem like it nucleates and grows. It seems like when the tension reaches a point that's suitable, it then just coats the DNA very quickly. One possibility is that it forms a filament on the DNA and so you end up with a cooperative loading of a large amount of protein in a very short period of time forming some kind of ultrastructure on the DNA. That will require us to do some more detailed structural analysis.

Beth Moorefield: In that regard, how does it compare with other DNA binding proteins involved in the DNA recombination?

Dr. Hickson: Completely differently. They generally recognize in almost equimolar amounts a particular type of substrate, whereas there'll be tens of thousands of molecules of PICH on a long ultrafine bridge. The question is, why do you need tens of thousands? And you probably don't, but for some reason it may be that that's the only way that you could recognize the DNA quickly in anaphase, which happens very rapidly. You have to find the DNA; you have to decatenate it. The only way to do that is to basically cover the DNA and then get the Bloom and Topo III proteins covering the DNA as well, and then wherever the problem is you can deal with it. It can't be done by some slow tracking process, because anaphase would have finished by then; it'd be disastrous for the cell. We see it as a mechanism by which you waste a lot of protein on the DNA in order to get to the place you need to be as fast as you possibly can. That may be naïve, but that's how I see it.

Beth Moorefield: And it doesn't have to contend with nucleosomes; it would have to displace them?

Dr. Hickson: There was a hypothesis that PICH actively removes the nucleosomes, but we don't think that this is the case. The catalytically dead protein recognizes naked DNA with no nucleosomes, so it can't have removed the nucleosomes from that. The DNA has no nucleosomes on it, and that's probably because it's stretched. If you pull on nucleosomal DNA, the nucleosomes pop off the DNA simply because of pulling forces.

Beth Moorefield: What other properties of DNA have you been able to elucidate using the optical tweezer approach?

Dr. Hickson: You can measure a whole series of parameters to do with DNA structure, but it's not something that we've pursued in detail. That's a major interest of the lab we collaborate with, but we don't really analyze issues to do with how much you can stretch the DNA or what happens to it.

For example, perhaps counter-intuitively, if you stretch a piece of DNA too much, it actually starts to denature. The strands come apart. You can actually make bubbles in the DNA by pulling very hard on it. Of course, if there are any nicks in the DNA then the DNA strand will unravel, and the DNA will become single-stranded. Eventually, you can basically denature a piece of double-stranded 
DNA by pulling hard on it and eventually one strand will unravel from the other. That's what happens with extreme forces.

One of the problems that we have is that we don't really know how strong the spindle forces are in a cell. They've been estimated, but the estimates vary enormously. We don't know whether we're in the right ballpark with the optical tweezers. They are limited by how hard you could pull on a piece of DNA. So above about sixty piconewtons, it's really difficult to do anything. You can go down to about 0.5 piconewtons in the setup. That's the range that we have. If the mitotic spindle isn't in that range then we're not necessary studying the right phenomenon. How one would test accurately the strength of the mitotic spindle forces, I don't know. There've been estimates that vary by a hundredfold as to how strong it is.

Beth Moorefield: How is PICH regulated?

Dr. Hickson: PICH is regulated very strongly by a kinase called PLK1, polo-like kinase. It's phosphorylated by polo kinase, and polo kinase is required for its correct localization. It also localizes to the centromeres before anaphase.
Actually, PICH seems to regulate the localization of pololike kinase as well, which is curious, given how important polo is for mitosis. You can inactivate PICH in a human cell and the cells are still alive, but polo-like kinase seems not to be regulated properly and not to localize quite properly, so it's remarkable the cells are still alive. But that seems to be the key player in its regulation: PLK1.

Beth Moorefield: It's not subject to additional regulation by association with any of the other factors? It only works with ultrafine bridges?

Dr. Hickson: Not that we're aware of. The other factors on the bridge tend to be enzymes. They tend not to be modifying proteins. The only one that's a candidate for doing something interesting would be this protein called RIF1, because RIF1 is a targeting subunit for protein phosphatase 1. Actually, RIF1 might be part of the mechanism by which dephosphorylation events occur during mitosis around the bridge. We're studying that in some detail now. That's the only real candidate for a regulator. We've no evidence that RIF1 regulates PICH itself, but $\mathrm{PICH}$ does recruit it to ultrafine bridges. 


\section{$\$_{\text {CSH\& }}^{\infty}$ Cold Spring Harbor Symposia SYMPOSIA}

\section{A Conversation with lan Hickson}

Cold Spring Harb Symp Quant Biol 2017 82: 397-399 originally published online April 2, 2018 Access the most recent version at doi:10.1101/sqb.2017.82.034777

Creative This article is distributed under the terms of the

Commons http://creativecommons.org/licenses/by-nc/4.0/, which permits reuse and

License redistribution, except for commercial purposes, provided that the original author and source are credited.

Email Alerting Receive free email alerts when new articles cite this article - sign up in Service the box at the top right corner of the article or click here. 